\title{
Cardiorespiratory Responses during Cycle Ergometer Exercise with Different Ramp Slope Increments in Patients with Chronic Obstructive Pulmonary Disease
}

\author{
Nobuaki Miyahara, Ryosuke EdA, Hiroyasu Takeyama, Tadashi Maeda, Keisuke Aoe, Naomi KunichiKa, \\ Hiroyuki KoHARA and Mine HARADA*
}

\begin{abstract}
Objective The ramp exercise test has been widely used to evaluate cardiopulmonary responses to an incremental exercise load. This study was performed to clarify whether different slopes of the ramp exercise test influence exercise tolerance, exercise limiting factors, and respiratory pattern in patients with chronic obstructive pulmonary disease (COPD).

Subjects and Methods We applied three different slopes $(5 \mathrm{~W} / \mathrm{min}, 10 \mathrm{~W} / \mathrm{min}$ and $20 \mathrm{~W} / \mathrm{min}$ ) of the ramp exercise test in 9 patients with COPD and evaluated cardiopulmonary responses.

Results There were no significant differences in peak oxygen uptake, anaerobic threshold (AT), minute ventilation, heart rate, arterial oxygen saturation, expired tidal volume, or respiratory rate at the maximal load among the three different ramp exercises tested. AT could be determined in six of nine patients $(67 \%)$ at the slope of $5 \mathrm{~W} / \mathrm{min}$, in $8 / 9(89 \%)$ at the slope of $10 \mathrm{~W} / \mathrm{min}$, and in $9 / 9(100 \%)$ at the slope of $20 \mathrm{~W} / \mathrm{min}$.
\end{abstract}

Conclusion The findings suggest that the ramp slope does not affect exercise tolerance, exercise limiting factors, or respiratory patterns and each of these ramp slopes is useful for the evaluation of COPD. Ramp slopes of $10 \mathrm{~W} /$ min or $20 \mathrm{~W} / \mathrm{min}$ should be appropriate for the determination of AT.

(Internal Medicine 39: 15-19, 2000)

Key words: incremental exercise test, anaerobic threshold

\section{Introduction}

The ramp exercise test is an incremental exercise test in which the exercise load is increased continuously and linearly (1). This test has been widely used for clinical purposes in recent years, because it can be used to determine both the maximal oxygen uptake $\left({ }_{\mathrm{V}} \mathrm{O}_{2}\right.$ max) and the maximal minute ventilation (VE max) for a short period of time. This test may also be used for the determination of anaerobic threshold (AT) based on respiratory gas analysis (2).

For patients with chronic obstructive pulmonary disease (COPD) showing reduced exercise tolerance, the setting of a relatively small load such as $10 \mathrm{~W} / \mathrm{min}$ or $20 \mathrm{~W} / \mathrm{min}(3,4)$ in the ramp exercise test has been reported. However, a standard method for incremental exercise has not yet been established in these patients. A major factor causing exercise limitation for COPD patients is reduced pulmonary function, and other factors include deconditioning, cardiac factors and symptomatic dyspnea $(5,6)$. The respiratory pattern in COPD patients may vary from rapid and shallow to deep and slow $(7,8)$. It is not known whether ramp slope during exercise testing influences exercise tolerance, exercise limiting factors, or respiratory pattern in COPD patients, or which slope is the most appropriate for testing patients with COPD. In the present study, we employed three different slopes $(5 \mathrm{~W} / \mathrm{min}, 10 \mathrm{~W} / \mathrm{min}$ and $20 \mathrm{~W} / \mathrm{min}$ ) for the ramp exercise test to help clarify these issues.

\section{Subjects and Methods}

\section{Subjects}

We studied nine patients with stable COPD. The diagnosis of COPD was made using the standards of the American Thoracic Society (9). The study patients were selected based on the presence of a forced expiratory volume in $1 \sec \left(\mathrm{FEV}_{1.0}\right)$ less than $70 \%$ predicted, $\mathrm{FEV}_{1.0}$ /forced vital capacity (FVC) ratio less than $70 \%$, residual volume $(\mathrm{RV}) /$ total lung capacity (TLC) ratio more than $45 \%$, and emphysematous changes seen on chest computed tomography scanning. Patients who had a

From the Department of Internal Medicine, Respiratory Disease Center, National Sanyo Hospital, Ube and *the Department of Internal Medicine II, Okayama University Medical School, Okayama

Received for publication November 24, 1998; Accepted for publication August 5, 1999

Reprint requests should be addressed to Dr. Nobuaki Miyahara, the Department of Internal Medicine, Respiratory Disease Center, National Sanyo Hospital, 685 Higashikiwa, Ube, Yamaguchi 755-0241 
MiYAHARA et al

Table 1. Anthropometric and Pulmonary Function Data in Nine Patients with Chronic Obstructive Pulmonary Disease

\begin{tabular}{ccccccccccc}
\hline $\begin{array}{c}\text { Patient } \\
\text { No. }\end{array}$ & Sex & Age & $\begin{array}{c}\text { Height } \\
(\mathrm{cm})\end{array}$ & $\begin{array}{c}\text { Weight } \\
(\mathrm{kg})\end{array}$ & $\begin{array}{c}\mathrm{FVC} \\
(l)\end{array}$ & $\begin{array}{c}\mathrm{FEV}_{1.0} \\
(l)\end{array}$ & $\begin{array}{c}\mathrm{FEV}_{1.0} / \mathrm{FVC} \\
(\%)\end{array}$ & $\begin{array}{c}\% \mathrm{FEV}_{1.0} \\
(\%)\end{array}$ & $\begin{array}{c}\mathrm{DLCO} \\
(\mathrm{ml} / \mathrm{m} / \mathrm{mmHg})\end{array}$ & $\begin{array}{c}\mathrm{RV} / \mathrm{TLC} \\
(\%)\end{array}$ \\
\hline 1 & $\mathrm{~F}$ & 72 & 153.2 & 41.0 & 1.51 & 0.55 & 36.4 & 34.2 & 11.7 & 56.2 \\
2 & $\mathrm{M}$ & 64 & 163.0 & 52.0 & 3.41 & 0.80 & 23.5 & 32.0 & 16.0 & 49.5 \\
3 & $\mathrm{M}$ & 76 & 165.0 & 45.0 & 2.03 & 0.65 & 32.0 & 30.0 & 10.1 & 64.4 \\
4 & $\mathrm{M}$ & 68 & 166.5 & 44.0 & 2.49 & 1.52 & 61.0 & 61.3 & 19.3 & 50.2 \\
5 & $\mathrm{M}$ & 76 & 161.0 & 46.0 & 2.00 & 0.87 & 43.5 & 42.9 & 4.9 & 66.4 \\
6 & $\mathrm{M}$ & 65 & 159.0 & 52.0 & 1.87 & 0.74 & 39.6 & 28.9 & 7.7 & 57.7 \\
7 & $\mathrm{M}$ & 69 & 164.0 & 45.0 & 3.11 & 0.98 & 31.5 & 41.0 & 6.4 & 53.5 \\
8 & $\mathrm{M}$ & 72 & 165.0 & 63.5 & 2.56 & 0.95 & 37.1 & 41.3 & 12.2 & 50.6 \\
9 & $\mathrm{M}$ & 78 & 170.0 & 54.0 & 2.18 & 0.81 & 37.2 & 35.7 & 9.2 & 57.8 \\
\hline Mean & & 71.1 & 163.0 & 49.2 & 2.35 & 0.87 & 38.0 & 38.6 & 10.8 & 56.3 \\
S.D. & & 5.0 & 4.8 & 6.9 & 0.61 & 0.28 & 10.3 & 9.9 & 4.6 & 6.1 \\
\hline
\end{tabular}

FVC: forced vital capacity, $\mathrm{FEV}_{1.0}$ : forced expiratory volume in 1 second, $\mathrm{FEV}_{1.0} / \mathrm{FVC}$ : ratio of forced expiratory volume in 1 second to forced vital capacity, $\% \mathrm{FEV}_{1.0}: \%$ of predicted forced expiratory volume in 1 second, DLCO: diffusing capacity, carbon monoxide, singlebreath method, RV/TLC: ratio of residual volume to total lung capacity.

history of right heart failure, resting $\mathrm{PO}_{2}$ less than 60 torr, or ischemic heart failure were excluded from the study. Patient characteristics are shown in Table 1.

\section{Pulmonary function tests}

Pulmonary function tests were performed using a rolling seal spirometer (Chestac-55V, CHEST, Tokyo). The complete study was performed 1 to 14 days prior to the exercise test. Lung volumes were determined by the He dilution method and single breath diffusing capacity was measured with a single breath diffusion technique. The predicted normal values for $\mathrm{FEV}_{1.0}$ were determined according to the method of Berglund et al (10).

\section{Exercise tests}

Exercise tests were performed on an electromagnetically braked cycle ergometer under continuous ECG, blood pressure, and arterial oxygen saturation $\left(\mathrm{SaO}_{2}\right)$ (using a pulse oximeter, PULSOX-7, Minolta) monitoring. Informed consent was obtained from all patients. Each subject repeated the ramp exercise test 3 times on 3 separate days within a 10-day period. Slopes for the ramp test were set at 5, 10 and $20 \mathrm{~W} / \mathrm{min}$. The order for administering the three ramp slopes was randomized. This ergometric equipment (Aerobike 232CLX, Combi) was designed to control both power and torque, regardless of the pedaling frequency, using a feed back control system. Following the warm-up exercise consisting of 2 minutes pedaling at $10 \mathrm{~W}$, the ramp exercise was started at a pedaling frequency of $60 \mathrm{rpm}$. The exercise intensity increment was continued until the subject could no longer maintain a pedaling frequency of $60 \mathrm{rpm}$.

Immediately after the completion of the test, patients were asked why they stopped the test and were requestioned to estimate the intensity of dyspnea and leg effort. The symptoms of the highest intensity were identified as the exercise limiting symptoms.

\section{Respiratory gas and data analysis}

Respiratory gas analysis was performed throughout the exercise test using a respiratory gas analysis system (Aero Monitor AE-280, Minato Medical Science, Osaka) consisting of a zirconia oxygen analyzer, an infrared carbon dioxide analyzer, and a hot wire spirometer. The system was carefully calibrated before each test. Oxygen uptake $\left(\dot{\mathrm{V}} \mathrm{O}_{2}\right), \mathrm{CO}_{2}$ output $\left(\dot{\mathrm{V} C \mathrm{CO}_{2}}\right)$, expired tidal volume (TV), dead space volume/tidal volume (VT/VD) ratio, and respiratory rate were measured on a breathby-breath basis. Derived parameters such as minute ventilation $(\dot{\mathrm{V}} \mathrm{E}), \dot{\mathrm{V} E} / \dot{\mathrm{V}} \mathrm{CO}_{2}, \dot{\mathrm{V} E} / \dot{\mathrm{V}} \mathrm{O}_{2}$, respiratory exchange ratio (R; $\left.\dot{\mathrm{V}} \mathrm{CO}_{2} / \dot{\mathrm{VO}}_{2}\right)$, end-tidal $\mathrm{O}_{2}$, and end-tidal $\mathrm{CO}_{2}$ were calculated simultaneously and displayed with the heart rate and $\mathrm{V}_{2}$ on a computer (PC-9801, NEC, Tokyo) during the gas analysis.

The peak $\dot{\mathrm{VO}}_{2}$ was defined as the average of $\dot{\mathrm{V}}_{2}$ values over the last 15 seconds of each testing level. Anaerobic threshold (AT) was determined from gas exchange data by the Vslope method (2) using our software, which determines the turning point of the $\dot{\mathrm{V}} \mathrm{O}_{2}-\dot{\mathrm{V}} \mathrm{CO}_{2}$ relationship curve by two linear regression lines. The ratio of the increase in $\dot{\mathrm{V}} \mathrm{O}_{2}$ to increase in work rate (work efficiency: $\Delta \dot{\mathrm{V}} \mathrm{O}_{2} / \Delta \mathrm{WR}$ ) also was determined by linear regression of $\dot{\mathrm{VO}}_{2}$ plots from 1 minute after the start of ramping up to the point of the maximal load, using our software.

\section{Statistical analysis}

Statistical analysis was performed using StatView-J4.11 software and data are presented as the mean \pm SD. Repeatedmeasures analysis of variance (Repeated-measures ANOVA) was used to evaluate possible differences in the values for the aerobic parameters and other variables due to variations in the 


\section{Different Ramp Slope Increments in COPD}

ramp slope. The Fisher's protected least significant difference was used to isolate the mean value contributing to any significant $\mathrm{F}$ ratios. Differences were considered significant at $\mathrm{p}<0.05$.

\section{Results}

Table 2 shows changes in the peak $\dot{\mathrm{VO}}_{2}$ at three different slopes of the ramp exercise tests. There was no significant difference in the peak $\mathrm{V}_{2}$ among the three ramp slopes in the study patients.

Table 3 shows the values for each aerobic function obtained at the three different slopes studied in our nine patients. There were no significant differences in the values of ventilation, heart rate, and $\mathrm{SaO}_{2}$ at the maximal point of the exercise among the three ramp slopes tested. Exercise at all ramp slopes produced to the same values for tidal volume, respiratory rate, and VD/ VT ratio at the maximal load. The exercise limiting symptoms included dyspnea in seven patients and leg effort in two pa-

Table 2. Peak $\mathbf{V O}_{2}$ Values at Different Slopes of the Ramp Exercise Test

\begin{tabular}{cccc}
\hline $\begin{array}{c}\text { Patient } \\
\text { No. }\end{array}$ & \multicolumn{3}{c}{ Peak $\dot{\mathrm{VO}}_{2}(\mathrm{ml} / \mathrm{min})$ at a ramp slope of: } \\
& $5 \mathrm{~W} / \mathrm{min}$ & $10 \mathrm{~W} / \mathrm{min}$ & $20 \mathrm{~W} / \mathrm{min}$ \\
\hline 1 & 538 & 471 & 480 \\
2 & 760 & 734 & 794 \\
3 & 572 & 536 & 532 \\
4 & 447 & 449 & 413 \\
5 & 676 & 689 & 659 \\
6 & 556 & 527 & 618 \\
7 & 542 & 560 & 523 \\
8 & 779 & 743 & 814 \\
9 & 533 & 536 & 517 \\
\hline \multirow{2}{*}{ Mean } & 600.3 & 582.8 & 594.4 \\
S.D. & 112.5 & 110.8 & 138.6 \\
\hline
\end{tabular}

Peak $\dot{\mathrm{V}}_{2}$ peak oxygen uptake. tients. These pattern and frequency of these symptoms was unchanged by the ramp slopes used.

AT values determined by the V-slope method are shown in Table 4. AT values were determined in six of nine patients $(67 \%)$ at a slope of $5 \mathrm{~W} / \mathrm{min}$, in $8 / 9(89 \%)$ at a slope of $10 \mathrm{~W} / \mathrm{min}$, and in $9 / 9(100 \%)$ at a slope of $20 \mathrm{~W} / \mathrm{min}$. AT values were not significantly different between exercise at a slope of $5 \mathrm{~W} / \mathrm{min}$, $10 \mathrm{~W} / \mathrm{min}$, and $20 \mathrm{~W} / \mathrm{min}$ in five patients (patients 1, 3, 4, 6 and 9, Table 4).

Table 5 shows the maximal work rate (WR max), working efficiency $\left(\Delta \dot{\mathrm{VO}}_{2} / \Delta \mathrm{WR}\right)$ and performance time at each ramp slope. WR max values were increased progressively with increasing ramp slope, and differences in these values were significant among the three different ramp slopes tested. The $\Delta \dot{\mathrm{V}} \mathrm{O}_{2} / \Delta \mathrm{WR}$ and performance time decreased as the ramp slope increased, and differences in these values were significant among the three different slopes tested.

Table 4. Anaerobic Thresholds Determined Using the V-slope Method

\begin{tabular}{cccc}
\hline & \multicolumn{3}{c}{ AT (ml/min) at a ramp slope of: } \\
\cline { 2 - 4 } Patient & $5 \mathrm{~W} / \mathrm{min}$ & $10 \mathrm{~W} / \mathrm{min}$ & $20 \mathrm{~W} / \mathrm{min}$ \\
\hline 1 & 420 & 408 & 410 \\
2 & $\mathrm{ND}^{*}$ & 533 & 626 \\
3 & 545 & 441 & 455 \\
4 & 425 & 391 & 397 \\
5 & 651 & $\mathrm{ND}$ & 614 \\
6 & 556 & 510 & 540 \\
7 & ND & 429 & 434 \\
8 & ND & 557 & 543 \\
9 & 406 & 431 & 411 \\
\hline
\end{tabular}

AT: anaerobic threshold, *Not determined because of technical problem.

Table 3. Maximum Values of Aerobic Function on Ramp Exercise Testing

\begin{tabular}{lccc}
\hline & \multicolumn{3}{c}{ Ramp slope } \\
\cline { 2 - 4 } & $5 \mathrm{~W} / \mathrm{min}$ & $10 \mathrm{~W} / \mathrm{min}$ & $20 \mathrm{~W} / \mathrm{min}$ \\
\hline$\dot{\mathrm{VE}}(l / \mathrm{min})$ & $27.5 \pm 4.1$ & $26.9 \pm 5.0$ & $27.8 \pm 4.3$ \\
$\mathrm{SaO}(\%)$ & $90.2 \pm 4.3$ & $89.0 \pm 5.2$ & $90.7 \pm 4.1$ \\
$\mathrm{Heart}$ rate (beats/min) & $115.8 \pm 14.4$ & $113.0 \pm 17.2$ & $117.9 \pm 15.3$ \\
Respiratory rate (breaths/min) & $24.8 \pm 4.2$ & $24.7 \pm 4.4$ & $24.6 \pm 4.2$ \\
Expired tidal volume $(\mathrm{ml})$ & $1,183.8 \pm 140.7$ & $1,173.6 \pm 249.7$ & $1,214.3 \pm 204.9$ \\
VD/VT & $0.43 \pm 0.05$ & $0.44 \pm 0.05$ & $0.43 \pm 0.05$ \\
& & &
\end{tabular}

$\dot{\mathrm{VE}}$ : minute ventilation, $\mathrm{SaO}_{2}$ : arterial oxygen saturation, VD/VT: ratio dead space volume to tidal volume.

Each value represents the mean \pm standard deviation in nine patients studied. 
Table 5. Comparison of WR max, Work efficiency $\left(\Delta \dot{V}_{2} / \Delta W R\right)$ and Performance Time at Different Ramp Slopes

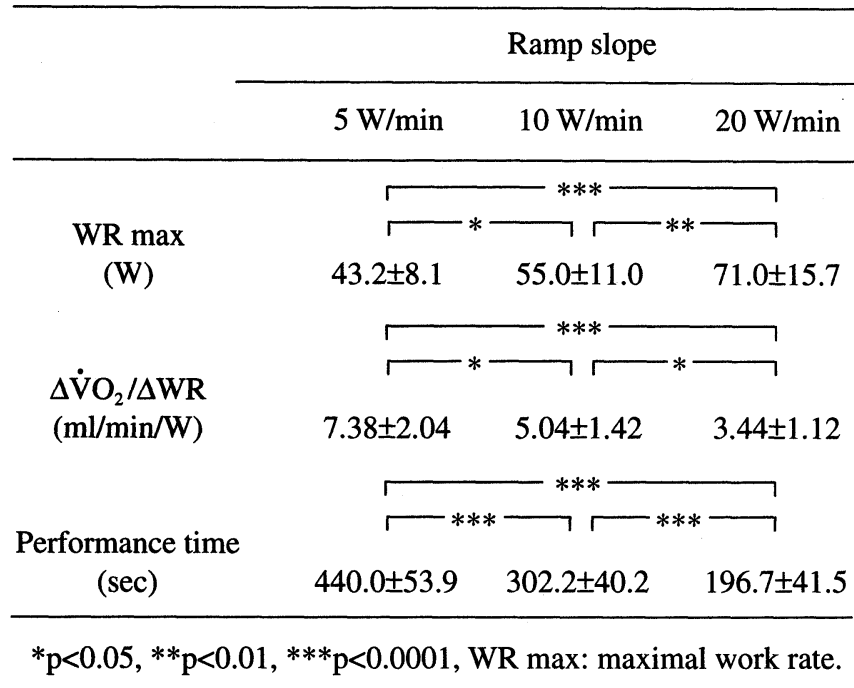

\section{Discussion}

The ramp exercise test is useful for measuring $\dot{\mathrm{V}}_{2}$ max, widely used as an indicator of exercise tolerance. This method is based on the application of a single load in a short period of time (1), and therefore the test has been introduced for evaluating exercise tolerance in both healthy and COPD patients. Reduced ventilatory reserve due to obstructive dysfunction is an exercise limiting factor for most patients with COPD. In some COPD patients, other exercise limiting factors include deconditioning, cardiac factors, and symptomatic dyspnea. These exercise limiting factors associated with COPD also are evaluable by the ramp exercise test. The respiratory pattern in COPD patients shows variation such as a rapid and shallow or deep and slow type. In the present study, we investigated the effects of three different ramp slopes on exercise tolerance, exercise limiting factors, and a respiratory pattern in COPD patients.

Cardiorespiratory responses to different loads on the ramp exercise test have been reported to be similar among healthy subjects when $\dot{\mathrm{VO}}_{2}$ max and AT values were examined by applying different loads during the test (11). In COPD patients with low exercise tolerance, however, prolonged exercise at a gentle slope of the ramp may cause leg fatigue, which may have a significant exercise limiting effect and decreased exercise tolerance. In contrast, our data indicate that there was no difference in peak $\dot{\mathrm{VO}}_{2}$ and AT values, as indicators of exercise tolerance, or in $\dot{\mathrm{VE}}, \mathrm{SaO}_{2}$, heart rate, or exercise limiting symptoms at the three different slopes tested. We also found no difference in the respiratory rate or expired tidal volume at the maximum exercise at the different ramp slopes tested. Respiratory pattern at the maximal load, which is determined by respiratory rate and expired tidal volume, was also not affected by the slope of the ramp exercise test.

The AT has been widely measured as an indicator of exer- cise tolerance for clinical evaluation (12). The V-slope method has been reported to be useful for evaluating AT in COPD patients based on respiratory gas analysis (13). This method is based on changes in $\dot{\mathrm{V}} \mathrm{O}_{2}$ and $\dot{\mathrm{V}} \mathrm{CO}_{2}$, both of which may be measured non-invasively. Using this method, however, it is difficult to determine the AT in some subjects because of difficulty determining the turning point of $\dot{\mathrm{VO}}_{2}-\dot{\mathrm{V}} \mathrm{CO}_{2}$ curve due to an excess of $\dot{\mathrm{V}} \mathrm{CO}_{2}$ caused by lactate accumulation, or because of failure to reach the AT at the maximum exercise (13). Our data show that AT was not successfully determined in one-third of the patients when the ramp slope of $5 \mathrm{~W} / \mathrm{min}$ was applied. This is probably due to moderate changes in $\mathrm{V}_{2}$ and $\dot{\mathrm{VCO}}_{2}$ leading to difficulty in determining the threshold when the ramp slope is modest and the performance time is long. Therefore, $10 \mathrm{~W} / \mathrm{min}$ or $20 \mathrm{~W} / \mathrm{min}$ appears to be an appropriate ramp slope for the determination of AT in COPD patients.

The work rate at the maximum exercise increased significantly, while work efficiency decreased as the ramp slope was increased. Similar results have been reported in healthy subjects $(14,15)$. The reason for these observations is that the difference in the actual exercise load from metabolic function subsequently induced by the exercise becomes greater as the ramp slope becomes steeper (14). In the present study, considerable differences were observed in the maximal work rate values at slopes of $5 \mathrm{~W} / \mathrm{min}$ versus $20 \mathrm{~W} / \mathrm{min}$. Accordingly, it is necessary to be careful about the condition how the ramp exercise test is set up when WR max is used as an indicator of exercise tolerance or when it is used as a criteria for prescribing a exercise therapy.

A slope of $20 \mathrm{~W} / \mathrm{min}$ produced extremely short performance times of about 3 minutes. To evaluate parameters such as Borg scale scores at each minute during exercise (16), an appropriate performance of 5 to 10 minutes is necessary. Selection of a ramp slope which will allow appropriate performance time is difficult in COPD. Our data suggest that few patients reach an appropriate performance time at a slope of $20 \mathrm{~W} / \mathrm{min}$. Therefore, to evaluate these parameters at each minute during exercise testing, a slope of $5 \mathrm{~W} / \mathrm{min}$ or $10 \mathrm{~W} / \mathrm{min}$ should be used for the ramp exercise test.

In conclusion, our data suggest that differences in ramp slope do not affect peak $\dot{\mathrm{VO}}_{2}$ or AT values, exercise limiting factors, or respiratory patterns in COPD patients and therefore, each ramp slope may be appropriate for the evaluation of a COPD patient. A slope of $10 \mathrm{~W} / \mathrm{min}$ or $20 \mathrm{~W} / \mathrm{min}$ should probably be used for determination of AT using the V-slope method in COPD patients. To evaluate parameters which need to be monitored at 1 minute intervals, a slope of $5 \mathrm{~W} / \mathrm{min}$ or $10 \mathrm{~W} / \mathrm{min}$ appears useful. Therefore, the most useful single slope is $10 \mathrm{~W} / \mathrm{min}$ for ramp exercise testing of COPD patients.

Acknowledgements: The authors would thank to Ms. Midori Nina and Mr. Shigeru Obata for their technical assistance. This study was supported in part by a grant of the Chugoku Region National Chest Hospitals Research Committee. 


\section{Different Ramp Slope Increments in COPD}

\section{References}

1) Whipp BJ, Davis JA, Torres F, Wasserman K. A test to determine parameters of aerobic function during exercise. J Appl Physiol 50: 217-221, 1981.

2) Beaver WL, Wasserman K, Whipp BJ. A new method for detecting anaerobic threshold by gas exchange. J Appl Physiol 60: 2020-2027, 1986.

3) Otsuka T, Kurihara N, Fujii T, Fujimoto S, Yoshikawa J. Effect of exercise training and detraining on gas exchange kinetics in patients with chronic obstructive pulmonary disease. Clin Physiol 17: 287-297, 1997.

4) Yoshida T, Chida M, Ichioka M, Makiguchi K, Tojo N, Udo M. Ventilatory response and arterial potassium concentration during incremental exercise in patients with chronic airways obstruction. Clin Physiol 11: 73-82, 1991.

5) Killian KJ, Leblanc P, Martin DH, Summers E, Jones NL, Campbell EJ. Exercise capacity and ventilatory, circulatory, and symptom limitation in patients with chronic airflow limitation. Am Rev Respir Dis 146: 935940, 1992.

6) Medoff BD, Oelberg DA, Kanarek DJ, Systrom DM. Breathing reserve at the lactate threshold to differentiate a pulmonary mechanical from cardiovascular limit to exercise. Chest 113: 913-918, 1998.

7) Gallagher CG, Younes M. Breathing pattern during and after maximal exercise in patients with chronic obstructive lung disease, interstitial lung disease, and cardiac disease, and in normal subjects. Am Rev Respir Dis 133: 581-586, 1986.

8) Epstein SK. Etiology of extubation failure and the predictive value of the rapid shallow breathing index. Am J Respir Crit Care Med 152: 545-549, 1995.

9) American Thoracic Society. Standards for the diagnosis and care of patients with chronic obstructive pulmonary disease. Am J Respir Crit Care Med 152: S77-121, 1995.

10) Berglund $E$, Birath G, Bjure J, et al. Spirometric studies in normal subjects: I. Forced expirograms in subjects between 7 and 70 years of age. Acta Med Scand 173: 185-191, 1963.

11) Davis JA, Whipp BJ, Lamarra N, Huntsman DJ, Frank MH, Wasserman K. Effect of ramp slope on determination of aerobic parameters from the ramp exercise test. Med Sci Sports Exerc 14: 339-343, 1982.

12) Wasserman K, McIlroy MB. Detecting the threshold of anaerobic metabolism in cardiac patients during exercise. Am J Cardiol 14: 844-852, 1964.

13) Sue DY, Wasserman K, Moricca RB, Casaburi R. Metabolic acidosis during exercise in patients with chronic obstructive pulmonary disease. Use of the V-slope method for anaerobic threshold determination. Chest 94: 931-938, 1988.

14) Hansen JE, Casaburi R, Cooper DM, Wasserman K. Oxygen uptake as related to work rate increment during cycle ergometer exercise. Eur $\mathrm{J}$ Appl Physiol 57: 140-145, 1988.

15) Takaishi T, Ono T, Yasuda Y. Relationship between muscle fatigue and oxygen uptake during cycle ergometer exercise with different ramp slope increments. Eur J Appl Physiol 65: 335-339, 1992.

16) Teramoto S, Fukuchi Y, Nagase T, Matsuse T, Shindo G, Orimo H. Quantitative assessment of dyspnea during exercise before and after bullectomy for giant bulla. Chest 102: 1362-1366, 1992. 